\title{
SECUENCIA CONSTRUCTIVA: QUINTA PLATAFORMA DE LA GRAN PIRÁMIDE HUACA PUCLLANA
}

\author{
HERNÁN SilVERA LA TORRE \\ PROYECTO DE INVESTIGACIÓN, CONSERVACIÓN Y PUESTA EN VALOR HUACA PUCLLANA
}

\section{RESUMEN}

El sitio arqueológico Huaca Pucllana se encuentra en el distrito de Miraflores, departamento de Lima, el cual constituye un centro ceremonial administrativo, correspondiente a la cultura lima. Compuesto por una gran pirámide con 7 plataformas.

La quinta plataforma se ubica en la parte más elevada de la gran pirámide, estas son importantes porque registran elementos arquitectónicos que se distribuyen y definen las últimas 11 etapas y momentos constructivos de la fase constructiva IV, ubicadas en la época Lima Tardío. Así mismo evidencian la ocupación más tardía correspondiente a la transición Lima-Wari. Los resultados nos proporcionan información para entender los últimos momentos de función y uso de la arquitectura, definiendo elementos arquitectónicos de mucha complejidad en el uso del espacio y de diferentes técnicas constructivas; así como superposiciones de elementos arquitectónicos, que fueron rellenados constantemente.

Estos datos demuestran la importancia de las construcciones monumentales Lima; los mismos que se relacionan a un sistema complejo y poco conocido de una organización político-religiosa. En la construcción y el uso del espacio de estos centros religiosos, resaltan las actividades rituales como complemento al trabajo corporativo; siendo los más conocidos: los rituales del rompimiento de vasijas, banquetes rituales, colocación de ofrendas humanas, elaboración de hoyos pequeños y luego la colocación de ofrendas. En las etapas más tardías la arquitectura sufre cambios, especialmente en los accesos, los que se vuelven mucho más restringidos y complejos; además los acabados de muros y pisos son simples y toscos.

Palabras claves: Huaca Pucllana, Lima, arquitectura, plataforma. 


\section{Abstract}

The archaeological site Huaca Pucllana is located in the district of Miraflores, department of Lima, which constitutes an administrative ceremonial center, corresponding to the Lima culture. Composed of a large pyramid with 7 platforms.

The fifth platform is located in the highest part of the great pyramid, these are important because they register architectural elements that are distributed and define the last 11 stages and constructive moments of the construction phase IV, located in the Late Lima period. They also show the later occupation corresponding to the Lima-Wari transition. The results provide us with information to understand the last moments of function and use of the architecture, defining architectonic elements of great complexity in the use of the space and of different constructive techniques; As well as superpositions of architectural elements, which were constantly refilled.

These data demonstrate the importance of the monumental constructions Lima; The same that relate to a complex and little-known system of a political-religious organization. In the construction and the use of the space of these religious centers, they emphasize the ritual activities as a complement to the corporate work; Being the best known: rituals of breaking pots, ritual banquets, placing of human offerings, making small holes and then placing offerings. In later stages architecture undergoes changes, especially in accesses, which become much more restricted and complex; In addition the finishes of walls and floors are simple and coarse.

KeYwords: Huaca Pucllana, Lima, architecture, platform.

\section{INTRODUCCIÓN}

El presente artículo es el resultado del análisis arquitectónico de la Quinta y el acceso a la Sexta plataforma de la gran pirámide, correspondiente a las excavaciones realizadas bajo la dirección de la Dra. Isabel Flores.

El sitio arqueológico conocido actualmente como Huaca Pucllana constituye uno de los más importantes del valle bajo del Rímac por sus dimensiones y riqueza de evidencia arquitectónica y mueble. Los trabajos llevados a cabo en el sitio por el Proyecto de Investigación, Conservación y Puesta en Valor Huaca Pucllana así lo demuestran.

El sitio arqueológico está ubicado en el distrito de Miraflores, provincia de Lima; geográficamente, en la costa central, en la margen izquierda del valle bajo del río Rímac, a 153 m.s.n.m, y a 2 km. del litoral marino. Ocupa actualmente 6 hectáreas.

El sitio fue ocupado durante el periodo de los Desarrollos Regionales (200-700 d.C.) perteneciendo a las fases tardías del estilo Lima. Probablemente fue construido y ocupado entre el 500 y el 700 d.C. (Figura 1) 


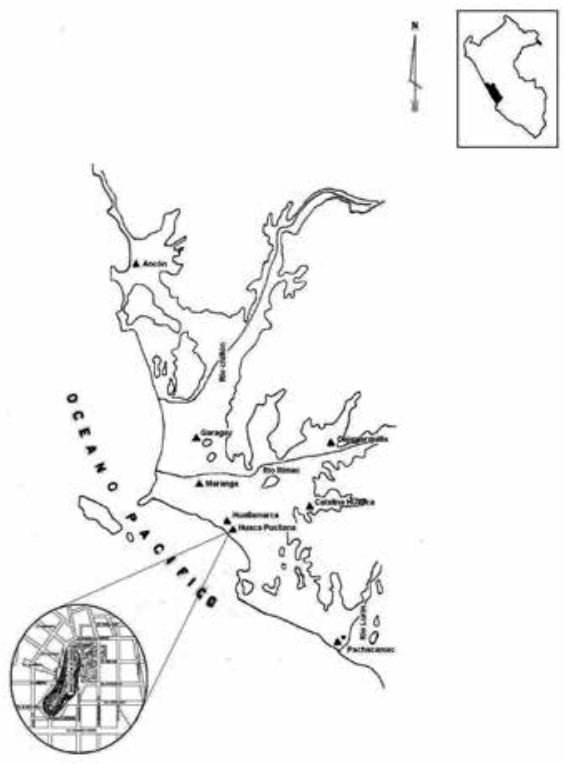

Figura 1: Plano general de Huaca Pucllana, tomado de Flores et, al 2012

El complejo Arqueológico Huaca Pucllana fue estudiado y visitado por varios viajeros e investigadores, entre ellos por viajero Alemán Ernesto Midendorf en el siglo XIX; también se han realizado estudios de archivos coloniales: Maria Rostworowski recupera la información de los documentos donde se especifica que hacia fines del siglo XVI el sitio fue propiedad del curaca Don Pedro Chumbi Charnan, principal del señorío de Huatca, quien señala que el sitio, en ese tiempo, tenía por nombre Pullana o Puliana.

Cuando llegaron los incas al valle de Lima, Pucllana se encontraba abandonada varios siglos. Era una Ñawpa Llacta que quiere decir "pueblo viejo", y considerada como un lugar sagrado.

A fines del siglo XIX y la primera década del siglo XX el científico alemán Max Uhle plantea la contemporaneidad de la Huaca Juliana, con los sitios de Nieveria, Maranga, Copacabana, y Pachacamac, después de haber estudiado el valle del Rímac. En 1925 Alfred Kroeber excava en la Huaca Juliana, Maranga y Bajada Balta y los resultados los publica en 1954 definiendo el estilo Proto-Lima. En 1935, Pedro Villar Córdova definió la zona Arqueológica Juliana como perteneciente a una población agrícola y publicó una clasificación de sitios en base a descripciones de arquitecturas y técnicas de construcción. En 1941 Julio C. Tello con su colaborador Toribio Mejia Xesspe inicia el rescate Arqueológico en el sitio y ordena la suspensión de los trabajos que venía haciendo la compañía urbanizadora de Surquillo la cual venía destruyendo la zona Arqueológica. En 1950 Louis Stumer efectuó reconocimientos arqueológicos y exploraciones en la costa central. En 1954 publica una clasificación de asentamientos prehispánicos, en donde distingue a los centros ceremoniales del Rímac. En la década del sesenta del siglo pasado el sitio Huaca Juliana había quedado dividido en dos fracciones de terreno situados en la zona residencial de Miraflores las que habían sido separadas por el trazado de la calle Independencia. En 1966 Thomas Patterson, publica una propuesta clasificatoria de la alfarería Lima que llama "Estilo Lima” señalando además que los sitios de Maranga, Pucllana y Trujillo pudieron haberse construido a 
fines de la fase seis. En 1967 a consecuencia de la destrucción y con la finalidad de conocer el monumento Arqueológico, conservarlo y ponerlo en valor, la municipalidad de Miraflores conjuntamente con un equipo de arqueólogos formado por Isabel Flores y Carlos Guzmán, logran recuperar, tejidos y cerámica; lamentablemente estos trabajos no tuvieron la continuidad deseada.(Flores 2005:26).

Desde 1981 hasta la fecha se vienen realizando los trabajos Arqueológicos con la dirección de la Dra. Isabel Flores, bajo un convenio con el Ministerio de Cultura y la Municipalidad de Miraflores, logrando importantes hallazgos e investigaciones acerca de la población de la cultura Lima.

Esta sociedad conocida como la cultura Lima estaba formada por una serie de grupos humanos unidos por una misma cultura la cual al parecer no alcanzaba una organización estatal sino más bien curacal. Se organizaban a partir de los grandes centros ceremoniales - administrativos. Vivian en grandes centros urbanos muy complejos como el de la Huaca Pucllana, que fue un lugar sagrado, un centro de poder local que administraba toda la producción de la zona (Flores 2005). Los pobladores se dedicaban a la agricultura. Habían desarrollado la tecnología de la irrigación trayendo agua desde el río Rímac convirtiendo las tierras en áreas fértiles. La pesca y el marisqueo eran también actividades de subsistencia muy importantes, que se desarrollaban tanto en las orillas como en la alta mar utilizando embarcaciones hechas de totora.

Pucllana se encuentra dividida en dos sectores: la Gran Pirámide y el Complejo Noreste, baja adyacente en donde se realizaron actividades relacionadas al culto religioso: ritos y sacrificios en honor a sus dioses y residencias de los sacerdotes gobernantes depositando ofrendas en hoyos pequeños. La pirámide se compone de 7 plataformas, rampas, patios, recintos, pasadizos, escalinatas, banquetas pintadas de amarillo que definirían espacios sagrados.

Adyacente a la pirámide por el extremo Este se encuentra el sector administrativo conformado por recintos, pasadizos, patios con rampas, banquetas y depósitos de ofrendas, destinados a las labores públicas y de gobierno de la población. Actividades de intercambio debieron ser frecuentes en esta zona.

El presente artículo corresponde a los trabajos de excavación que se realizaron en la quinta plataforma y el acceso entre la quinta y sexta plataforma de la gran pirámide Huaca Pucllana, donde se han encontrado gran cantidad de elementos arquitectónicos superpuestos mezclados con rellenos constructivos lo cual dio lugar a excavar el espacio, con la finalidad de definir la las secuencia constructiva de la etapa tardía de la ocupación Lima en Pucllana. En este proceso se ha podido definir elementos arquitectónicos, depósitos y rellenos superpuestos que fueron encontrados en la temporada de excavación 2008 - 2009.

Estas actividades se han realizado como parte del programa de investigaciones ejecutadas del "Proyecto de Investigación, Conservación y Puesta en Valor de Huaca Pucllana"; dirigido por la Dra. Isabel Flores Espinoza; bajo el convenio suscrito entre el Ministerio de Cultura y la Municipalidad de Miraflores.

Los objetivos de las excavaciones en esta área fueron buscar información para entender los últimos momentos de función y uso de la arquitectura del acceso entre la quinta y sexta plataforma de la gran pirámide. Definir diferentes niveles estratigráficos que corresponden a etapas y momentos constructivos en la época tardía. Dentro de los depósitos encontrados se encontraron elementos arquitectónicos que se asociaban a accesos, rellenos constructivos, contexto especial de acumulación de desechos que forman parte de la estratigrafía de la quinta plataforma. 
El espacio donde se ubica la quinta plataforma se encuentra en la parte superior central de la gran pirámide de Huaca Pucllana, entre la cuarta y sexta plataforma. Se trata de espacios abiertos y el acceso entre la quinta y sexta plataforma de la gran pirámide, donde se encuentran una superposición de pisos, rellenos y contextos especiales (Figura 2). El acceso fue sellado posteriormente, posiblemente, entre la transición del Intermedio Temprano al Horizonte Medio. Todos estos elementos arquitectónicos fueron superpuestos por rampas, pisos, rellenos, que servirían luego como acceso que transporta posiblemente hacia el lado oeste con acceso a recintos de la sexta plataforma, luego, fue clausurado, depositando sobre ella una gran acumulación de desechos, compuesto por una gran cantidad de vegetales: ají, lúcuma, pacae, maíz, calabaza, maní; moluscos, pescado, roedores, mezclados con ceniza, donde posiblemente quemaron parte de los alimentos, derramando líquido, luego se sedimentaria. En algún momento, el material estuvo en descomposición, ya que se encontraron insectos, atraídos por la descomposición de los materiales orgánicos, mezclados con instrumentos de textilería: agujas enteras y fracturadas, husos con hilo, punzones de hueso; fragmentos de cerámica del alfar Pucllana naranja, gris entre otros (Figura 2).

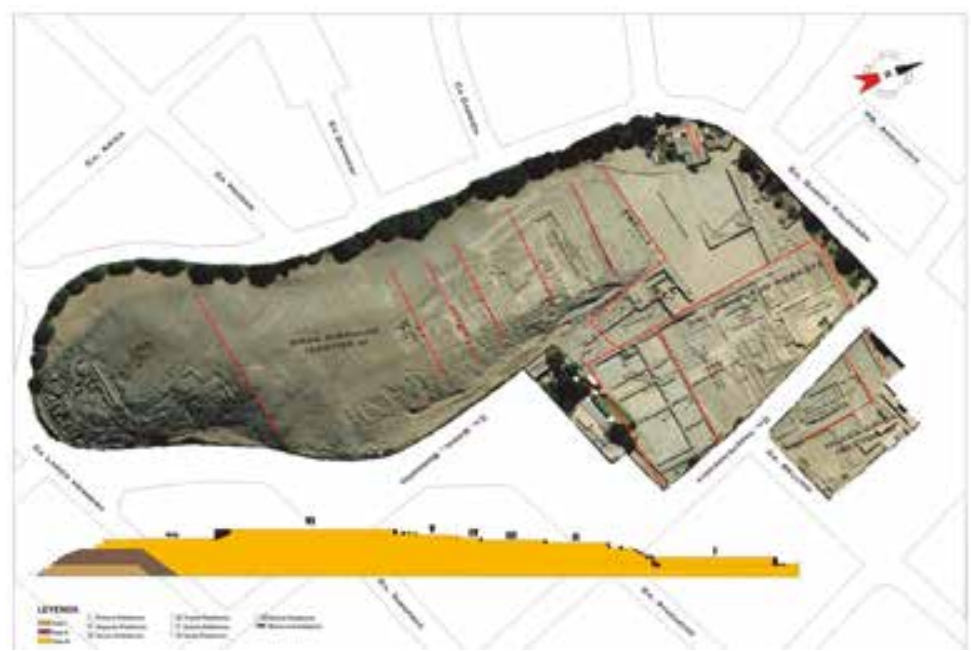

Figura 2: Vista de planta y perfil de la ubicación de la quinta plataforma de la gran pirámide Huaca Pucllana, tomado de flore, 2005 con modificaciones.

De las cuales se definieron etapas y momentos constructivos, de la plataforma V. Estos elementos arquitectónicos son complejos; están compuestos por rampas, pisos. Cada uno pertenece a un momento constructivo o de remodelación, y que son parte de etapas constructivas tardías, Los muros fueron remodelados constantemente; asimismo fueron reutilizados en diferentes etapas y momentos constructivos sin tener un buen acabado. Aparentemente, acondicionaban los accesos sin estética ni simetría, pues los acabados examinados son muy burdos.

\section{Secuencia constructiva de huaca Pucllana}

Los estudios realizados respecto de la fase constructiva III, últimas etapas constructivas en Huaca Pucllana demuestran los diferentes cambios en cuanto a la distribución y uso de los espacios. 
La Huaca Pucllana estuvo conformada por tres fases constructivas. La primera conformaba construcciones a base de tapiales concentrándose por el extremo sur de la gran pirámide. La segunda fase constructiva estuvo edificada por adobes paralelepípedos cuadrangular y cúbicos, concentrado por el extremo sur de la pirámide. La tercera fase constructiva fue elaborada con adobes paralelepípedos rectangulares ampliándose por el extremo norte del sitio.

Para la fase constructiva III, la arquitectura emplea adobes paralelepípedos rectangulares y principalmente, cantos rodados y arena para los rellenos (Flores 2005-56). En tal fase la gran pirámide se dividió en 7 plataformas, cada una de ellas están conformadas por plazas y recintos, asociados con diferentes elementos arquitectónicos, (Ccencho 2007).

En la plataforma se vislumbra diferentes etapas y momentos constructivos involucrando en cuanto al tiempo a la fase III b, del horizonte medio 1B, relacionado al estilo Nievería (Flores 2005).

Estos momentos se caracterizaron por la presencia de espacios abiertos con presencia de pintura amarilla y ejecución de actividades sagradas. Para las etapas más tardías se construyen espacios pequeños con pasadizos, recintos pequeños (Ríos y Ccencho 2009:91-118).

En los últimos momentos de construcción la Huaca Pucllana estuvo conformada por 7 plataformas (Flores 2005).

La pirámide sufrió gran cantidad de remodelaciones: entre plaza y plaza ${ }^{1}$, entre pasadizo y pasadizo, encontramos voluminosos rellenos de cantos rodados que sellan momentos constructivos.... Para construir sobre estas nuevas plazas y pasadizos (Flores 2005-36). Los patios están conformados por elementos arquitectónicos característicos que a cada momento arquitectónico lo diferencian uno de otro, así como por la presencia de postes en diferentes etapas constructivas.

Cada plataforma se compone de plazas con postes delimitado por muros con banquetas, lo que les daba una apariencia de escenario donde se observan los postes, de los cuales conjeturamos que debieron ser muy importantes para que esta arquitectura gire en torno a ellos y las actividades de las que dichos postes formaban parte (Flores 2005-35). En las plataformas se realizaron diferentes remodelaciones que estarían marcando las etapas y momentos constructivos que fueron sellados para seguir construyendo.

Los recintos, patios y plazas son remodelados numerosas veces, pero estas remodelaciones implican, casi siempre, el relleno de la construcción anterior para volver a construir sobre ella muchas veces lo mismo, parece que después de un tiempo de uso y normal funcionamiento de un ambiente, se procedía a su clausura. (Flores 2005-50).

Sin embargo, en otras ocasiones los ambientes sufren cambios radicales y los espacios abiertos como las plazas se reducen a ambientes más pequeños o se sustituyen accesos por plataformas, esto es lo común en los momentos finales de la ocupación y coincide con la mayor presencia de cerámica de estilo Nieveria (Flores 2005: 35).

Dentro de cada etapa, igualmente, sigue presentándose una serie de superposiciones y ligeros cambios en los espacios, transformaciones que están relacionadas a los momentos de uso y a los cambios ocurridos durante esos eventos (Flores 2005: 56).

1. El termino plaza fue remplazado por patios de acuerdo a las nuevas investigaciones. 
Del mismo modo se están realizando actividades rituales así como la elaboración de hoyos pequeños a modo de ofrendas. Se ha logrado definir y particular una actividad ritual bastante peculiar, la cual es denominada "ritual de los Hoyitos" y consiste en realizar hoyos de pequeño tamaño en la superficie del piso. (Flores 2005-35).

Por ende en esta fase se define una serie de caracterizaciones relacionadas con la presencia de la cerámica Nieveria. Por tanto la tercera fase constructiva de la Huaca Pucllana se encuentra caracterizada por las constantes remodelaciones de estructuras. Estas se encuentran elaboradas con los denominados adobitos rectangulares asociados a la presencia de los fragmentos de cerámica Lima 7, 8 , 9 y al estilo Nieveria. Dos fechados de radio carbónicos correspondientes a esta fase la ubicaron entre 650 y 700 años D.C. (Flores 2005:57).

Una subdivisión a esta última fase fue planteada en base a las últimas temporadas de excavaciones. La fase IIIa, la más temprana, estaría asociada a estructuras pintadas de amarillo mientras que la fase IIIb, un poco más tardía se asociaría a la construcción de la plataforma I y las remodelaciones del llamado Sector Administrativo (Ccencho 2006-19).

Tales remodelaciones en la arquitectura han tenido diferentes interpretaciones, desde cambios internos en el orden social hasta alteraciones climatológicas que habrían obligado a realizar construcciones no planificadas (Vásquez 1984: 8).

Las remodelaciones arquitectónicas responden a las necesidades políticas y organización de la sociedad en un momento de elevada complejidad en sus fases tardías (Marcone 2000).

Los cambios registrados en las edificaciones tienen que ver con los cambios cíclicos de regeneración y que estos habrían sido acompañados con actividades rituales (Segura 2001:167).

Lo cierto es que a partir de la época 7 de los diferentes centros ceremoniales de la cultura Lima empezaron a experimentar cambios en su configuración arquitectónica, muchos de ellos sufrieron remodelaciones mientras en otros aparentemente desaparecieron (Ríos 2008:30).

Un aspecto muy importante en la caracterización de la arquitectura de Pucllana es su constante relación con las actividades rituales o elementos naturaleza. Los elementos favoritos corresponden a cántaros grandes rotos intencionalmente cada vez que cambia de una etapa constructiva a otra. (Flores 2005).

Probablemente la sociedad Lima pasaba por una fuerte transformación social donde los grupos de poder o de la élite (muy probablemente sacerdotes) insistieron constantemente en una manipulación superestructura para controlar a la población. (Ríos 2008:132).

Los patios con estructuras escalonadas de Pucllana fueron definidos inicialmente por Segundo Vásquez en 1984, en el marco de los trabajos del Proyecto Arqueológico Huaca Pucllana; calificó estos espacios de como "grandes patios con un sistema de estructuras escalonadas compuestas de dos largas banquetas apoyadas sobre un muro que sirve a manera de contención o espaldar de mayor altura" (Vásquez 1984: 9). En relación a la quinta plataforma, la arquitectura registrada para la penúltima etapa constructiva era una plaza de gran dimensión, la cual es la culminación de una serie de remodelaciones previas, la última de las cuales consistió en la construcción de una banqueta ubicada a lo largo del lado sur con un acceso al sureste, el cual conecta un pasadizo de este a oeste, sobre el que se construyó una rampa, la cual conectaba a la sexta plataforma. En la quinta plataforma, se registraron importantes cambios arquitectónicos entre la penúltima y última fase de la misma. Estos cambios se relacionan no solamente con la construcción de nuevos espacios sobre lo que anteriormente era una plaza, sino que 
además esta última fue destruida y luego rellenada con material geológico natural e incluso, cultural. (Barreto, Ccencho, Chuchón, Silvera 2010:59-70).

La quinta y sexta plataforma difieren de las otras plataformas en cuanto a su forma, siendo la sexta la más alargada. Un detalle importante acerca de los Lima es un especial sentido de lo sagrado que se manifiesta en la arquitectura. Los diversos espacios usados son constantemente limpiados de manera que no se encuentran restos relacionados a las actividades usuales que se realizaban en ellos, pero cuando llega el momento de remodelar se depositan los desechos de los banquetes, ofrendas y sacrificios, de esta manera, conocemos muy bien los rituales y sacrificios realizados antes de la remodelaciones pero no tenemos materiales que nos permitan inferir acerca de las actividades cotidianas de estos (CAP-2007- 70).

\section{SECUENCIA CONTRUCTIVA DE LA QUINTA PLATAFORMA}

Se definieron 11 etapas constructivas las cuales nos permite al mismo tiempo definir los momentos constructivos permitiéndonos observar una serie de actividades que se realizaron en diferentes épocas de la quinta plataforma de la gran pirámide Huaca Pucllana.

\section{Primera Etapa constructiva}

La primera etapa constructiva de la época Lima tardía de la Gran Pirámide en Huaca Pucllana se ubicada en la parte superior central con un área aproximada de $950 \mathrm{~m}^{2}$, se trata de dos patios con estructuras escalonadas, pertenecen a una de las últimas etapas constructivas la cual se caracteriza por la complejidad y asociación con otras unidades arquitectónicas, para lo cual se menciona que debajo de este patio existen más patios mucho más tempranos.

El patio más antiguo por el extremo Oeste en el quinto nivel de la gran pirámide. Se encuentra completo y tiene un área de $963 \mathrm{~m}^{2}$. Tiene forma rectangular como los anteriores y una orientación longitudinal de Este a Oeste. Se han conservado tres de sus muros, faltando el del lado Oeste por cuestiones de colapso. El ancho en la base de estos varía de 1.20 a $2 \mathrm{~m}$; estos últimos debieron llegar a cuatro metros de altura mientras que el de $1.20 \mathrm{~m}$ que es el del lado Este no debió pasar de 2.8. Los tres muros conservados son reutilizados, los cuales presentan enlucido y solo el muro del sur posiblemente pintado de amarillo.

Presenta una banqueta de $2.48 \mathrm{~m}$ de ancho y $0.80 \mathrm{~m}$ de altura; se extiende a todo lo largo del lado Este del patio, se accede a ella por medio de una rampa por el extremo Norte, adosada en parte a la banqueta, de $3.90 \mathrm{~m}$ de largo, $3.60 \mathrm{~m}$ de ancho y $15^{\circ}$ de inclinación. Presenta además desgaste en la superficie lo cual se deduce que tuvo mucho uso; la pared lateral Sur está enlucida del color natural del barro. Lo mismo ocurre con la banqueta, aunque hay poca evidencia al respecto, luce bastante desgastada, aunque pareciera que sólo mostraba la cara de los adobes, creemos que esto es bastante improbable.

El piso posee $0.10 \mathrm{~m}$ de espesor y muestra huellas de desgaste, hoyos pequeños e improntas de tuzas de maíz al lado Sur. Su estado de conservación es regular, ha perdido el acabado en toda su extensión y hubo encima de él abundantes desechos asociados al relleno posterior de este ambiente con los cuales podría explicarse la presencia de las improntas de maíz. Al extremo Este hay una serie de depresiones al pie de la banqueta en las que, en algún momento, hubo vasijas. Este piso tuvo postes, de madera, ordenados de la siguiente manera: cuatro filas y siete columnas, haciendo un total de 28 postes; se trata de postes invertidos, de acuerdo a lo que se observa en los hoyos y debieron tener un diámetro de $0.25 \mathrm{~m}$. La distancia entre cada poste es de $3.3 \mathrm{~m}$, siendo esto un patrón regular. 
Durante este tiempo debió estar funcionando ya el acceso del SE que tiene $2 \mathrm{~m}$ de ancho; asimismo, es probable que haya existido un acceso en alguno de los extremos del muro del lado Oeste que no se ha conservado.

El espacio ocupado propiamente por el piso, correspondiente a un $48 \%$ del total del patio, fue rellenado con $370 \mathrm{~m}^{3}$ de cantos rodados y arena de color gris, previamente hubo apertura de hoyos pequeños de ofrendas y deposición de basura en grandes cantidades en la que resalta el maíz y los pescados, además dientes de tiburón blanco (Carcharodon carcharias). Esto implicó la desaparición del desnivel preparando el espacio del quinto nivel de la gran pirámide para un patio más reducido asociado a un recinto del cual carecemos de mayor información por la destrucción prehispánica y moderna.

Una vez concluido el relleno y el espacio queda nivelado, se construye un muro que divide en dos ambientes distintos, uno al Oeste y otro al Este; respecto del que está al Oeste se carece de mayor información que un aumento del nivel del piso que será visto luego. Centraremos nuestra descripción en lo que ocurre al Este.

El patio del lado Este tiene un área de $446 \mathrm{~m}^{2}$ y es de planta casi cuadrangular (20.7 m x $\left.21.60 \mathrm{~m}\right)$, conserva los cuatro muros que lo definen. El nuevo muro del lado Oeste tiene $1.25 \mathrm{~m}$ de ancho y es probable que su altura haya llegado hasta $2.5 \mathrm{~m}$. Posee una banqueta y dos accesos asociados; su acabado es enlucido con el color natural del barro. Los otros muros del lado Norte y Sur se encuentran enlucidos de color natural, a diferencia del muro del lado Sur que se encuentra enlucido y pintado de amarillo.

El patio cuenta con dos banquetas ubicadas en los muros Este y Oeste. La del lado Oeste se extiende por el muro Oeste entre los dos accesos ubicados en él. Tiene $2.15 \mathrm{~m}$ de ancho y $0.40 \mathrm{~m}$ de altura. Su acabado es enlucido con el color natural del barro. La banqueta del Este destaca por su complejidad. Se compone de una banqueta adosada a la esquina NE del patio, de $4.30 \mathrm{~m}$ de ancho y $0.45 \mathrm{~m}$ de altura. A esta banqueta se le adosan una especie de peldaño en el lado NE, este es de $2 \mathrm{~m}$ de largo, $1 \mathrm{~m}$ de ancho y $0.30 \mathrm{~m}$ de alto, su función debió ser la de permitir ascender sin mayores problemas al primer nivel de la estructura escalonada. Luego a la banqueta mencionada se le agrega encima otra de solo $3.30 \mathrm{~m}$ de ancho que se adosa al muro respaldar pero no tiene contacto con el muro Norte, pues se halla a casi $3 \mathrm{~m}$ de este; termina más al Sur que la banqueta del primer nivel. Todo el conjunto parece estar destinado a permitir el ascenso a la máxima altura en la parte central y Sur de este patio. Este conjunto de banquetas posee como acabado el enlucido con el color natural del barro y ha sido sometida a tratamientos diversos de conservación debido al colapso de la ladera que amenazaba seriamente su existencia.

Estas banquetas presentan grafitis realizados por incisiones que forman figuras geométricas: rectángulos y cuadrados, además de líneas paralelas.

El piso se encuentra en regular estado de conservación y tiene $10 \mathrm{~cm}$. de espesor, mostrando algunas huellas de quema en su superficie. El rasgo más notorio es la presencia de hoyos de postes y, restos de algunos de estos (en el extremo Sur). Están organizados en cinco columnas de seis y deben ser de madera de guarango y están en posición invertida. La distancia promedio entre ellos es de 2,80 m.

Este patio ha contado con tres accesos: dos al Oeste y uno en la esquina SE. Este último es el mismo que el del patio oeste que le antecede. Los otros dos se hallan a cada extremo de la banqueta de lado Oeste, el del Sur tiene casi $2 \mathrm{~m}$ de ancho y el del Norte solo $1 \mathrm{~m}$. Ambos tienen evidencia de hoyos a los lados lo cual implicaría cierta restricción en el acceso (Figura 3). 


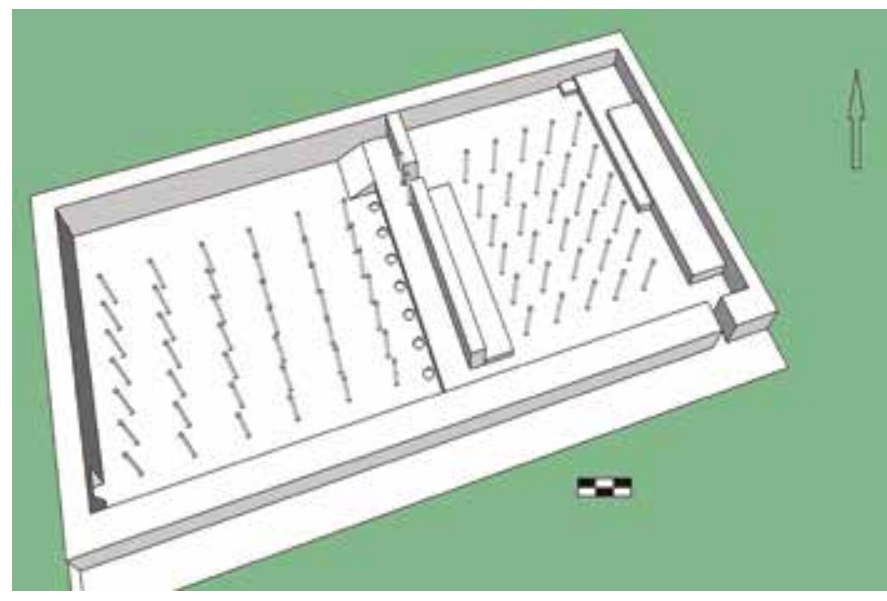

Figura 3: Isometría de la primera etapa constructiva.

\section{SEgUNDA ETAPA CONSTRUCTIVA}

Consiste en dos patios al mismo nivel, por el extremo Oeste fue nivelado con el patio con banquetas superpuestas. Con un acceso en la parte central hacia el Norte, presenta postes, y es un espacio mucho más grande en comparación a la plaza que se encuentra al extremo este de las banquetas superpuestas, con un acceso en la parte SE.

Los patios sufren cambios en cuanto a los niveles ya que para el extremo Oeste del patio es rellenado con cantos rodados arena, grumos de barro, tierra, con un espesor de $0.80 \mathrm{~m}, 300 \mathrm{~m}^{3}$, para nivelar con relación al extremo Este, colocando un piso de $0.05 \mathrm{~m}$ espesor, quedando dos patios divididos por un muro en la parte central y los dos accesos al extremo Norte y Sur, manteniendo los postes que posiblemente fueron como una evidencia de acceso restringido. Solo se evidenciaron 8 postes de madera de unos $20 \mathrm{~cm}$ de diámetro, no necesariamente alineados. El patio del extremo Este sigue manteniendo sus características sin ninguna modificación (Figura 4).

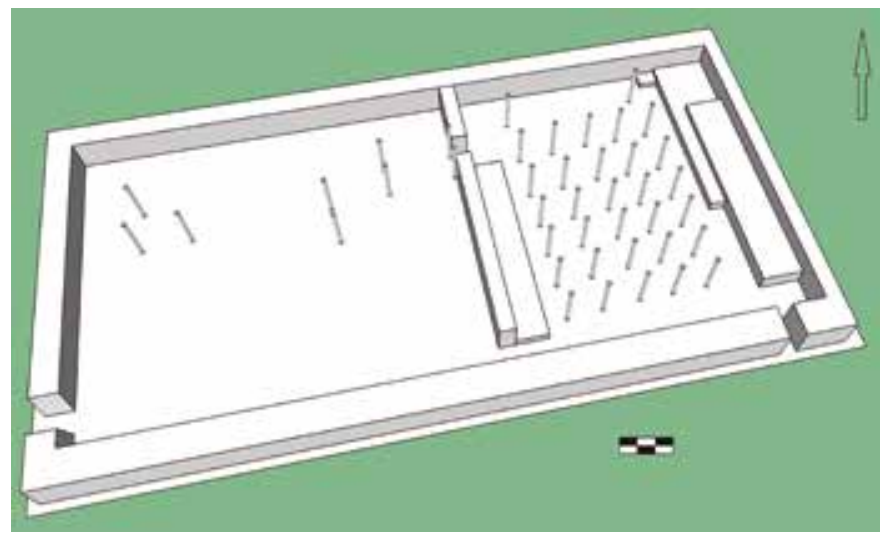

Figura 4: Isometría de la segunda etapa constructiva. 


\section{Tercera ETAPa Constructiva}

Consiste en dos patios con postes, con el patio del extremo Oeste a un nivel superior con relación al patio con banquetas superpuestas; descendiendo por una rampa y el acceso Nor-central del patio de $1 \mathrm{~m}$ de ancho.

Los cambios que se dan en esta etapa constructiva son pequeños y tienen que ver con los accesos al recinto del lado Oeste. El recinto Oeste es rellenado con una capa de $0.30 \mathrm{~m}$ de cantos rodados y arena gris, esto implica un volumen de $180 \mathrm{~m}^{3}$, para luego colocar otro piso; implicando un desnivel de poco más de $0.30 \mathrm{~m}$ respecto del patio del lado Este, para solucionar esto, se construyen rampas de acceso, la mejor conservada es la del lado NE que tiene $3.40 \mathrm{~m}$ de largo y $0.30 \mathrm{~m}$ de altura con un acabado de enlucido del color natural del barro, en superficie tiene evidencia de desgaste. Fuera de las rampas no hay mayores diferencias entre los dos patios salvo la cantidad de postes que han sido reducidos a 8 que no necesariamente están alineados. Sobre esto lo que hay es una sucesión de pisos y desechos, los pisos están con evidencia de uso.

Es notorio que este relleno carece de cerámica vinculada al estilo Nievería en alguna de sus variantes, todo es Lima tardío, sólo en los pisos posteriores aparece el componente Nievería (Figura 5).

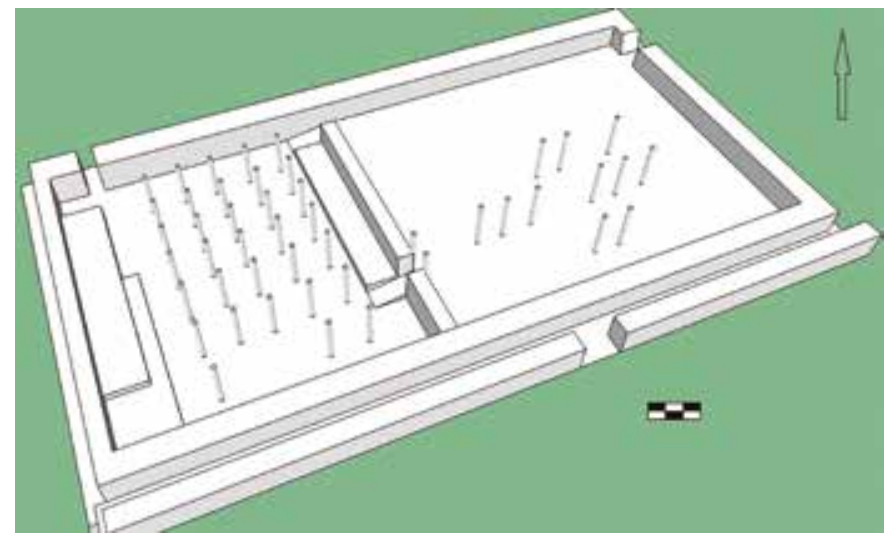

Figura 5: Isometría de la tercera etapa constructiva.

\section{Cuarta Etapa Constructiva}

Se trata de un espacio de $285 \mathrm{~m}^{3}$, cubierto por un relleno de cantos rodados, arena y tierra suelta, para ser superpuesto por un piso componiendo un espacio abierto, se trata de un patio de $950 \mathrm{~m}^{2}$, forma rectangular, con una orientación longitudinal de Este a Oeste. Presenta un piso de $0.10 \mathrm{~m}$ de espesor con postes alineados de unos $0.20 \mathrm{~m}$ de diámetro, aparentemente invertidos, Está compuesto por 7 filas X 8 columnas. Aparentemente presenta un acceso en el extremo SE de $2 \mathrm{~m}$. Los muros Este, Oeste y Norte se encuentran enlucidos con un color natural, a diferencia del muro sur que se encuentra pintado de amarillo. Estos muros son reutilizados de las etapas más tempranas. El muro Oeste no se evidencia, ya que el área se encuentra colapsada. El extremo Norte esta correlacionado con el pasadizo de $2 \mathrm{~m}$ de ancho, y $48 \mathrm{~m}$ largo aproximadamente. Tiene además un acceso central hacia el norte de $2 \mathrm{~m}$. que da hacia la cuarta plataforma (Figura 6). 


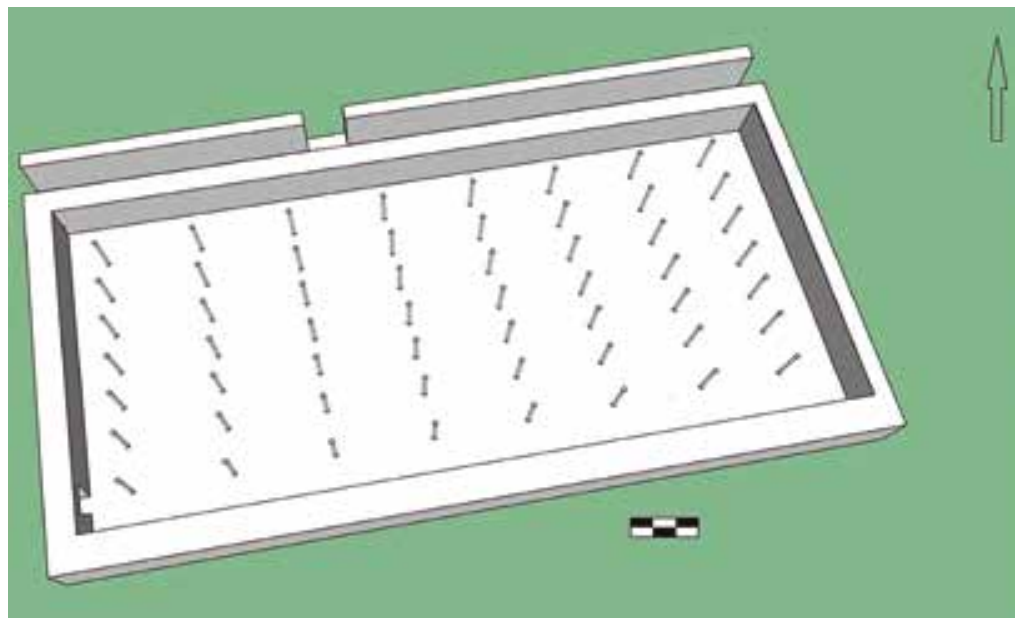

Figura 6: Isometría de la cuarta etapa constructiva.

\section{Quinta ETapa Constructiva}

Se trata de un espacio que superpone a la cuarta etapa constructiva, el cual está compuesto por un piso plano compacto de $0.20 \mathrm{~m}$ espesor con acabado de enlucido ligero, con un área de $950 \mathrm{~m}^{2}$, componiendo un espacio abierto. Se trata de un patio de forma rectangular, con una orientación longitudinal de Este a Oeste, con postes alineados de unos $0.20 \mathrm{~m}$ de diámetro alineados aparentemente de forma invertida, el área está compuesto por 7 filas y 8 columnas, y presenta un acceso en el extremo $\mathrm{SE}$ de $2 \mathrm{~m}$. El muro Norte se encuentra enlucido con un color natural. Debió medir aproximadamente $4 \mathrm{~m}$ y su espesor de $2 \mathrm{~m}$. A diferencia del muro sur que se encuentra pintado de amarillo, estos muros son reutilizados de las etapas más tempranas. No hay evidencias del muro Este y Oeste, ya que el área se encuentra colapsado. Por el extremo Norte está correlacionado con el pasadizo de $2 \mathrm{~m}$ de ancho, y $48 \mathrm{~m}$ largo aproximadamente, tiene un acceso central, hacia el Norte de $2 \mathrm{~m}$, que da hacia la cuarta plataforma. Continúa con el mismo patrón arquitectónico de la cuarta etapa constructiva.

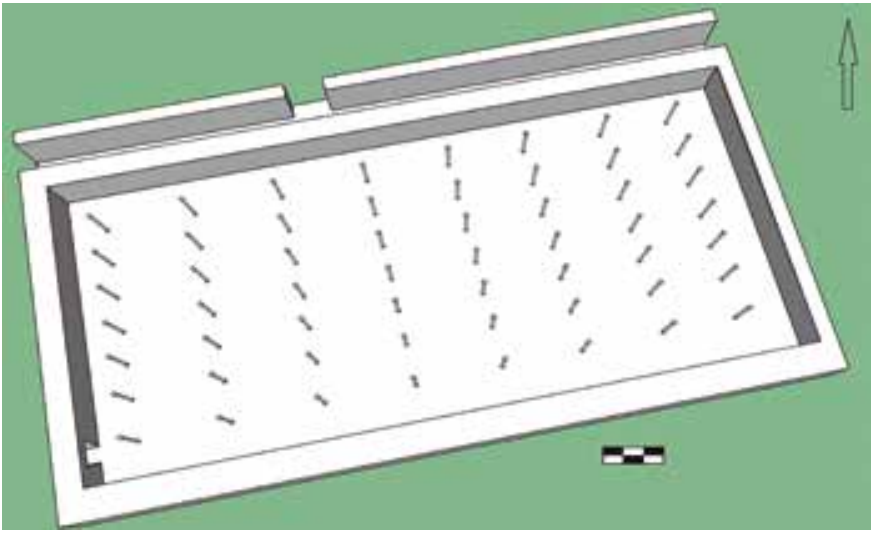

Figura 7: Isometría de la quinta etapa constructiva. 


\section{Sexta Etapa Constructiva:}

Se trata de un espacio abierto que se superpone a la quinta etapa constructiva, tratándose de una plaza rectangular de $19.80 \mathrm{~m}$ de ancho, $47.60 \mathrm{~m}$ largo, con un área total de $950 \mathrm{~m}^{2}$, Está compuesto por un piso plano compacto de $0.10 \mathrm{~m}$ espesor con acabado de enlucido ligero, con hoyos pequeños como depósitos de ofrendas y postes alineados, distribuidos en a lo largo del patio, En la sección SE, hubieron dos postes, componiendo un espacio libre, tratándose de un patio de forma rectangular, con una orientación longitudinal de Este a Oeste, con postes alineados de unos $0.20 \mathrm{~m}$ de diámetro, aparentemente invertidos, compuesto por 7 filas, 15 columnas, con un total de 105 postes, con una distancia de $1.50 \mathrm{~m}$. Aparentemente presenta un acceso en el extremo SE de $2 \mathrm{~m}$. El muro norte se encuentra enlucido con un color natural, que debieron medir aproximadamente $4 \mathrm{~m}$ con un espesor de $2 \mathrm{~m}$, a diferencia del muro sur que se encuentra pintado de amarillo, estos muros son reutilizados de las etapas más tempranas. No hay evidencias del muro Este y Oeste, ya que el área se encuentra colapsado .Por el extremo Norte esta correlacionado con el pasadizo de $2 \mathrm{~m}$ de ancho, $48 \mathrm{~m}$ largo aproximadamente, con un acceso central hacia el Norte de $2 \mathrm{~m}$, hacia la cuarta plataforma. Continúa con el mismo patrón arquitectónico de la quinta Etapa Constructiva. (Figura 8)

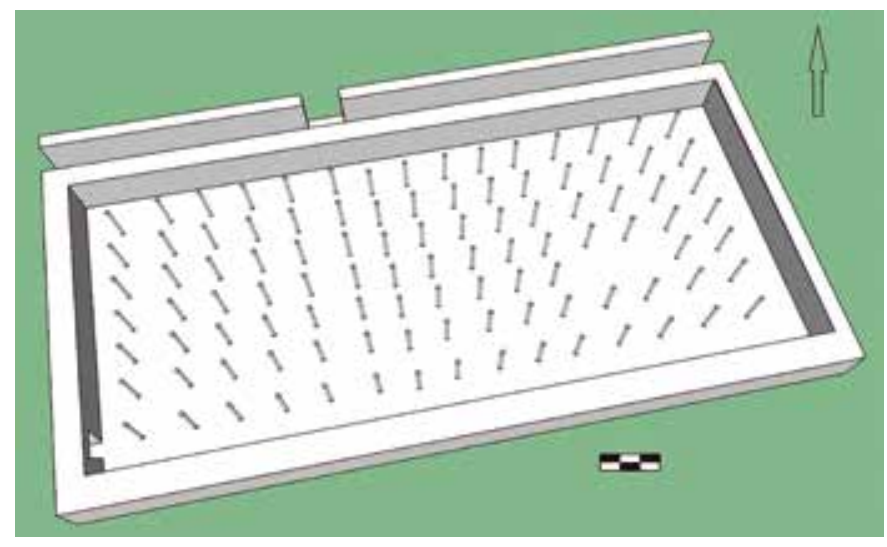

Figura 8: Isometría de la sexta etapa constructiva.

\section{Séptima ETAPa Constructiva:}

Primer momento constructivo. Espacio abierto de forma rectangular, de $10 \mathrm{~m}$ ancho, $40 \mathrm{~m}$ largo, formando un patio abierto, presenta un acceso en la parte norcentral de $2 \mathrm{~m}$ de ancho, por el extremo SE presenta otro acceso de $2 \mathrm{~m}$ de ancho aproximadamente, que se relaciona como parte de un muro Norte, formando un pasadizo, que corre de este a oeste de $2 \mathrm{~m}$ de ancho al extremo sur este. Se abre un espacio reducido. El patio está compuesta por un piso plano compacto con postes alineados a lo ancho con una distancia de $1.50 \mathrm{~m}$. Hay 14 filas de 6 postes aproximadamente.

Segundo momento constructivo. Tiene una relación en el extremo SE, se clausura el pasadizo que se distribuye hacia el extremo oeste con relleno de adobes paralelepípedos largos, en forma de emparrillado, acondicionando un espacio con una banqueta que se distribuye de Norte a Sur de unos $0.70 \mathrm{~m}$. de ancho, $0.40 \mathrm{~m}$ alto, adosado por el oeste a un muro de $0.50 \mathrm{~m}$ de ancho. Los mismos que por el Norte se adosan al muro perimétrico que estuvo pintado de amarillo. Aparentemente el espacio reducido forma un espacio rectangular. 
Tercer Momento Constructivo. En el extremo Sur el patio sigue sufriendo cambios, donde aparece como un acceso entre la Quinta y Sexta Plataforma, elaborando una rampa de Este a Oeste que tiene una inclinación de 45ำ $14 \mathrm{~m}$, de largo, $1.50 \mathrm{~m}$ ancho, Luego desciende hacia el extremo Oeste y al mismo tiempo ampliándose en cuanto al ancho hacia el extremo Sur con $8 \mathrm{~m}$ de largo, $5 \mathrm{~m}$ ancho, $45^{\circ}$ de inclinación, reduciéndose por el extremo SE como una rampa mucho más corta y delgada de unos $6 \mathrm{~m}$ largo, $1.30 \mathrm{~m}$ ancho, adosados a dos muros laterales, que accede hacia la sexta plataforma,

Cuarto Momento Constructivo. Al extremo oeste de la rampa sufre cambios, cubriendo la rampa Oeste del tercer momento constructivo, acondicionando un piso plano compacto de unos $010 \mathrm{~m}$ espesor, donde aparece un vano de $1.20 \mathrm{~m}$ ancho, compuesto por dos muros, de $1.50 \mathrm{~m}$ ancho $3 \mathrm{~m}$ de alto aproximadamente. Por el Norte, el muro se adosa a un muro eje, al igual que por el Sur se adosa a un muro eje. Por el SE, se sigue manteniendo la rampa que accede hacia la sexta plataforma, para lo cual se nota que los materiales empleados para la construcción son adobes paralelepípedos largos reutilizados, pero siguiendo la técnica constructiva (Figura 9).

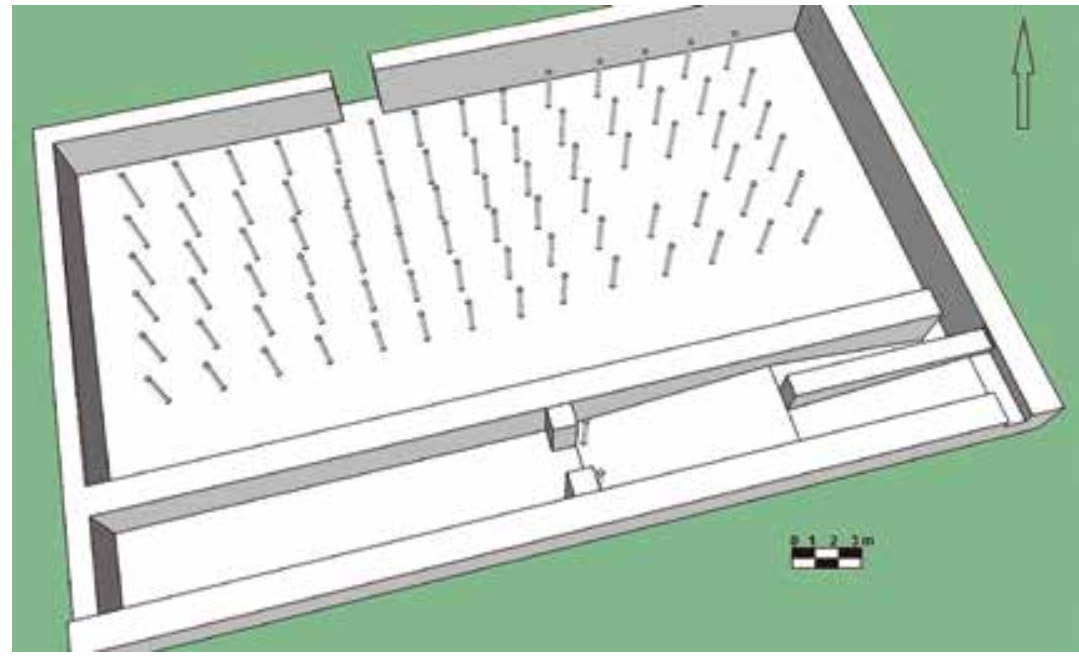

Figura 9: Isometría de la séptima etapa constructiva.

\section{Octava Etapa Constructiva}

En el acceso entre la Quinta y Sexta Plataforma de $40 \mathrm{~m}$. largo x $5 \mathrm{~m}$. de ancho se produce un cambio arquitectónico en la parte central. Con un sistema de accesos asociados con banquetas, en media luna. Al mismo tiempo la superficie al extremo Este es inclinada, considerada como una rampa, para el extremo Norte, se asocia con una banqueta en forma de media luna de $2.46 \mathrm{~m}$. de largo, $1.35 \mathrm{~m}$ de ancho, $0.39 \mathrm{~m}$. de alto máximo, $17 \mathrm{~cm}$. alto mínimo, adosado al muro Norte eje y al muro Este del acceso, se presenta luego un acceso entre los dos muros, el muro Norte tiene $1.58 \mathrm{~m}$. largo, $1.03 \mathrm{~m}$ de ancho adosado al muro eje Norte, el muro Sur opuesto tiene $1.46 \mathrm{~m}$. de largo, $1.10 \mathrm{~m}$ de ancho, adosado al muro Sur eje, presentan dos postes de madera a cada lado hacia el extremo este de unos 0.15 $\mathrm{m}$ diámetro, $3 \mathrm{~m}$ de alto aproximadamente, a modo de acceso restringido controlado, por el este se adosa a la banqueta de forma ovalada tiene $2 \mathrm{~m}$. de largo, $1.09 \mathrm{~m}$ de ancho, $35 \mathrm{~cm}$. de alto, presentando tres remodelaciones, superpuestas una sobre otras con un hilada de adobes y barro compacto como 
enlucido. Se Adosa por el Sur al muro eje, dentro de un recinto rectangular de $2.60 \mathrm{~m}$ de largo, $5 \mathrm{~m}$. de ancho, sobre un piso compacto de $0.10 \mathrm{~m}$ de espesor del piso.

Por el Este parte central del, recinto se encuentra otro acceso de $0.60 \mathrm{~m}$. de ancho, el muro Norte tiene $1.70 \mathrm{~m}$. de largo, $1.06 \mathrm{~m}$ de ancho, $3 \mathrm{~m}$ de alto aproximadamente adosado por el Norte al muro eje Norte, al otro extremo se encuentra el muro similar de $1.44 \mathrm{~m}$. de largo, $1.12 \mathrm{~m}$. de ancho, $3 \mathrm{~m}$ de alto aproximadamente, adosado al muro eje Sur, en las esquinas Este de los muros se encuentran dos postes uno a cada lado, a modo de accesos de control de $0.15 \mathrm{~m}$ de diámetro, $3 \mathrm{~m}$ de alto aproximadamente, Por el extremo Este se mantienen las rampas. una que asciende hacia el Oeste, y el otro que asciende hacia el Este, luego se une con la rampa que tiene $2 \mathrm{~m}$ de ancho, que el transporta al Este, luego, en la parte superior hacia el lado Sur se encuentra un vano entre un muro de $0.60 \mathrm{~m}$ espesor, 3 $\mathrm{m}$ de alto aproximadamente orientado de Norte a Sur (Figura 10).

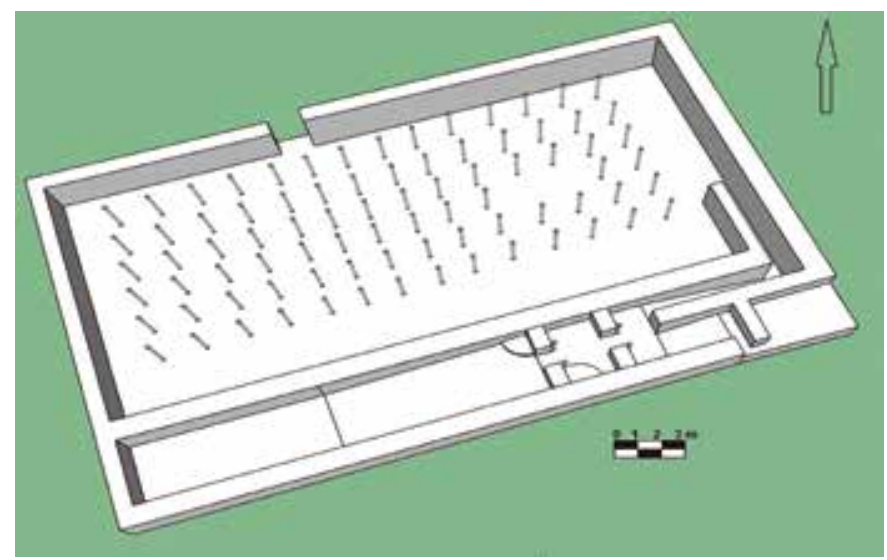

Figura 10: Isometría de la octava etapa constructiva.

\section{Novena Etapa Constructiva}

Tratándose de un patio de unos $0.40 \mathrm{~m}$. de largo aproximadamente, $17 \mathrm{~m}$. de ancho y es de forma rectangular. Presenta un acceso al extremo norte de $2.60 \mathrm{~m}$. ancho. El a patio es de superficie plana compacto de $0.10 \mathrm{~m}$ espesor, con postes de madera alineados de unos $0.20 \mathrm{~m}$ de diámetro, aparentemente invertidos, compuesto por 7 filas x 15 columnas alineados, por el extremo Sur, presenta una banqueta con enlucido delgado color natural orientado de este a oeste, de $1.60 \mathrm{~cm}$. de ancho, $50 \mathrm{~cm}$. de alto, $37 \mathrm{~m}$ de largo aproximadamente y tiene como respaldar el muro Sur, de $1 \mathrm{~m}$ de ancho, $38 \mathrm{~m}$. de largo de Este a Oeste.

El patio presenta dos accesos: por el extremo Norcentral, uno de $2 \mathrm{~m}$ de ancho, que se conecta con la cuarta plataforma, por el SE, se presenta un acceso de $1.50 \mathrm{~m}$ hacia el sur y doblando por medio de una rampa hacia el Oeste, para luego acceder a un espacio rectangular de $25 \mathrm{~m}$ de largo, $5 \mathrm{~m}$ de ancho, con piso plano de unos $0.10 \mathrm{~m}$ de espesor con un acabado irregular, luego doblando hacia el extremo Este por medio de un pasadizo con piso compacto y acabado irregular, con mucha presencia de desgaste de $3 \mathrm{~m}$ ancho, $11 \mathrm{~m}$ largo, luego doblando al Sur, hacia la sexta plataforma. Los muros del patio siguen siendo reutilizados de etapas mucho más tempranas (Figura 11). 


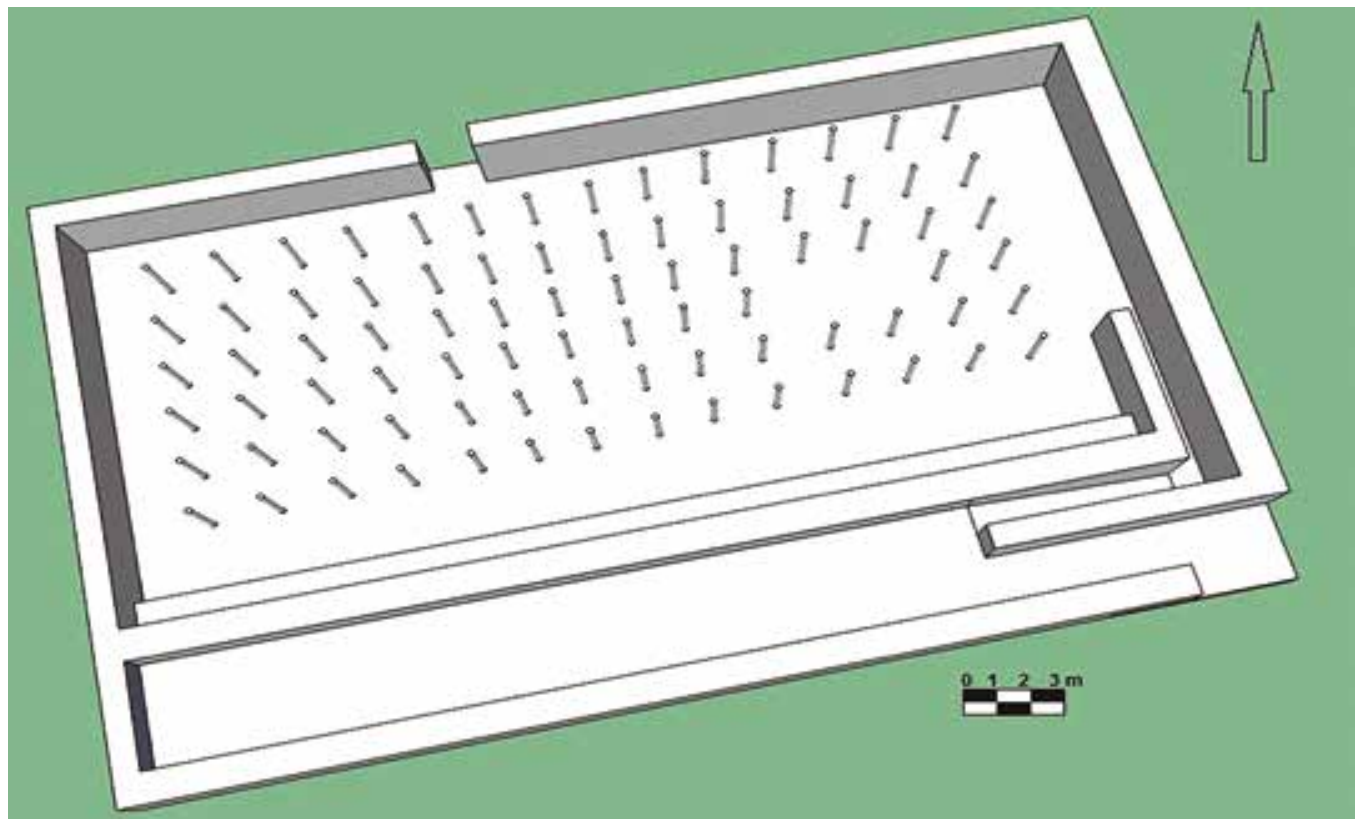

Figura 11: Isometría de la novena etapa constructiva.

\section{Décima Etapa Constructiva}

Tratándose de un patio de unos $0.40 \mathrm{~m}$. de largo aproximadamente, $17 \mathrm{~m}$. de ancho y de forma rectangular, presenta un acceso al extremo norcentral de $2.60 \mathrm{~m}$. ancho. Ingresando al patio de superficie plana compacto de $0.10 \mathrm{~m}$ espesor, con postes de madera alineados de unos $0.20 \mathrm{~m}$ de diámetro, aparentemente invertidos, compuesto por 7 filas x 15 columnas alineados con un total de 105 postes, a una distancia de $1.50 \mathrm{~m}$. En la parte Este, presenta un murete de cañas delgas de $0.02 \mathrm{~m}$ de diámetro, $3 \mathrm{~m}$ de alto, murete en forma de "L" adosados a dos postes por los extremos y plantados en el piso compactados con argamasa de barro compacto a una profundidad de $0.06 \mathrm{~m}$, las cañas se encuentran alineadas y adosadas, tiene $5 \mathrm{~m}$ de Este a Oeste, $2.60 \mathrm{~m}$ de Norte a Sur, por el extremo Sur presenta una banqueta con enlucido delgado color natural orientado de Este a Oeste, de $1 \mathrm{~m}$. de ancho, $0.50 \mathrm{~m}$. de alto, $37 \mathrm{~m}$ de largo aproximadamente y tiene como respaldar el muro Sur, de $1 \mathrm{~m}$ de ancho, $38 \mathrm{~m}$. de largo de Este a Oeste.

La banqueta sufrió una modificación, en la parte central se realiza una forma de entrada y una rampa de acceso restringido de Norte a Sur que transporta hacia el pasadizo entre la Quinta y Sexta Plataforma. El Muro eje Sur del patio que sirve como respaldar a la banqueta es destruido y depositado al mismo tiempo una ofrenda de un individuo adulto sobre una camilla con ofrendas de vasijas de cerámica y mates, al costado en un nivel más alto un individuo femenino sacrificado sin camilla ni ofrendas, a los costados óseos humanos. Luego superpuesto por otro muro mucho más angosto de unos $1 \mathrm{~m}$ de ancho y $3 \mathrm{~m}$ alto aproximadamente, la rampa de este a oeste sigue funcionando, que para clausurar el momento anterior depositaron alimentos y desechos a lo largo de la rampa y pasadizo, para el extremo Sur continuo al acceso de $1 \mathrm{~m}$. de ancho (Figura 12). 


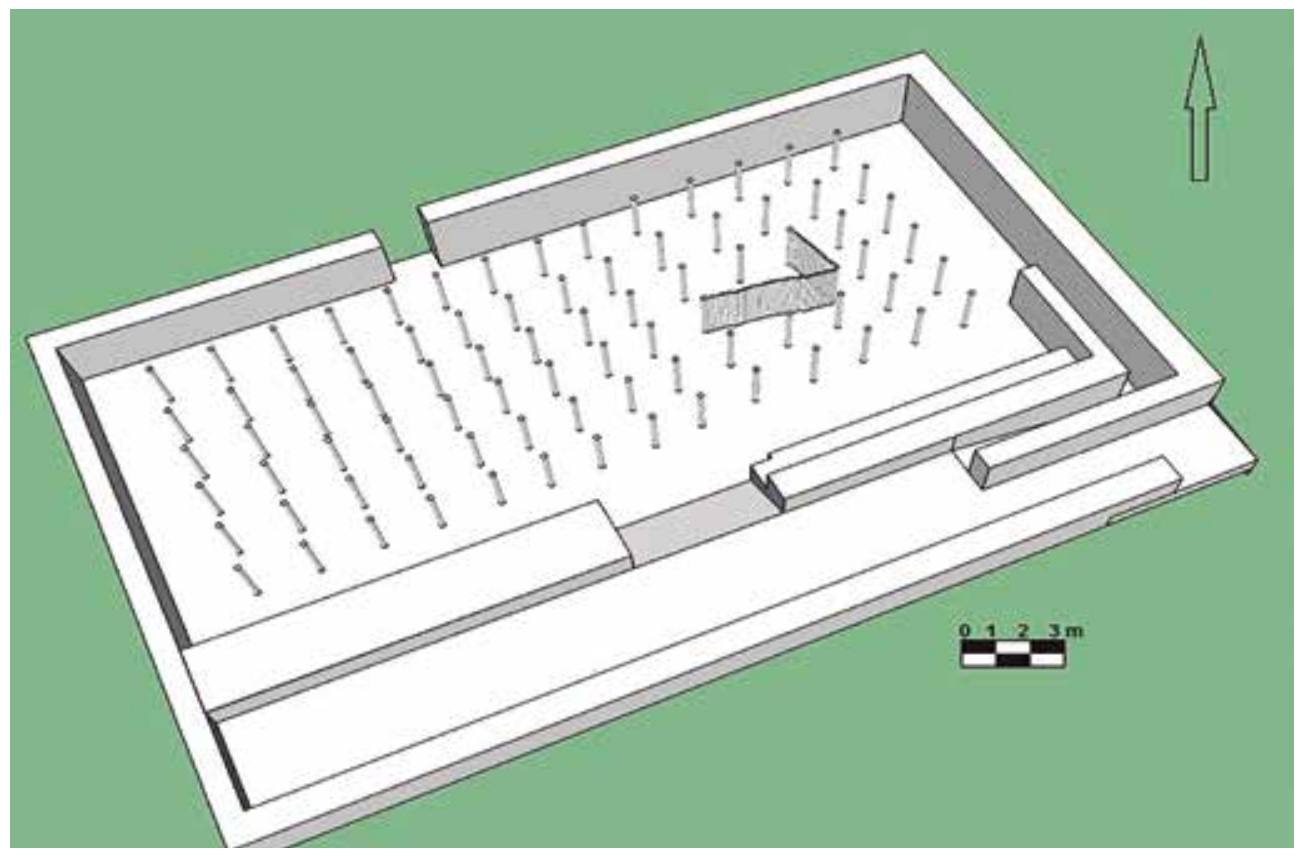

Figura 12: Isometría de la décima etapa constructiva.

\section{Décimo Primera Etapa Constructiva}

Trata de un patio rectangular de $40 \mathrm{~m}$ de largo, 17 de ancho, de $680 \mathrm{~m} 2$, presenta 3 secciones divididas por muros que se unen hacia el Norte, salen dos muros de $0.80 \mathrm{~m}$. de ancho, presentando postes de madera alineados, la que mayor concentración de postes mantiene es la sección central de $0.15 \mathrm{~m}$ de diámetro. En el extremo Este, forman un acceso hacia el pasadizo entre la Quinta y Sexta Plataforma divididos por Muros. El acceso hacia la Sexta plataforma es por medio del acceso de rampa por el extremo SE, al mismo tiempo por la parte sur central como un acceso de rampa de unos $45^{\circ}$ de inclinación, con $0.50 \mathrm{~m}$ de ancho, $1 \mathrm{~m}$ largo, adosado a una plataforma de $1 \mathrm{~m}$ de largo, $0.70 \mathrm{~m}$ de ancho, superpuesto por una pequeña plataforma al extremo este de $0.30 \mathrm{~m}$ de ancho, $0.40 \mathrm{~m}$ largo, asociado por el Sur con una rampa corta de $0.45 \mathrm{~m}$ de ancho $0.40 \mathrm{~m}$ de largo con $45^{\circ}$ de inclinación aproximadamente, que accede al acceso de entre la quinta y sexta plataforma, donde se levanta dos muros de $0.50 \mathrm{~m}$ de ancho, $8 \mathrm{~m}$ de largo, $3 \mathrm{~m}$ de alto aproximadamente, adosado a otro muro sur Oeste de $3 \mathrm{~m}$ de largo, $0.50 \mathrm{~m}$ de ancho, formando un recinto rectangular con acceso hacia el Este.

Posteriormente se construyen las tumbas funerarias Wari en los diferentes espacios de la Quinta y Sexta Plataforma (Figura 13). 


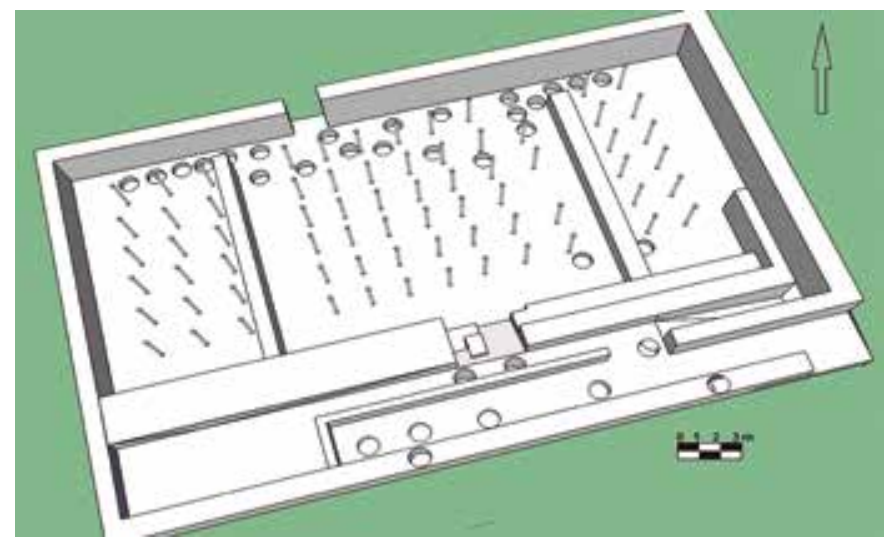

Figura 13: Isometría de la décima primera etapa constructiva.

\section{INTERPRETACIONES}

La primera, segunda y tercera etapa constructiva están conformadas por patios con estructuras escalonadas, por el extremo Oeste con un patio hundido, y al Este con banquetas superpuestas y accesos de rampas con postes alineados, de alguna forma manteniendo el patrón arquitectónico de lo que vendría hacer la fase constructiva III , tardí 3, caracterizada por el uso de los adobes paralelepípedos largos y pintura amarilla. En donde posiblemente realizaron actividades ceremoniales como como es el caso del rompimiento de vasijas como lo menciona (Ríos y Ccencho, 2009), sumado a ese ritual la elaboración de pequeños depósitos de ofrendas, asociados con cerámica del alfar Pucllana Nieveria.

Los patios con estructuras escalonadas son, los espacios arquitectónicos de mayor jerarquía registradas en Pucllana; comportamiento que se pueden extenderse a otros centros religioso administrativos contemporáneos de la Cultura Lima. Además representa la mayor proporción de espacios que se encuentra dentro de las pirámides.

La cuarta, quinta y sexta etapa constructiva están conformadas por patios o espacios abiertos de carácter ceremonial en los que se realizaron remodelaciones que están relacionados con los momentos constructivos, como también la elaboración de depósitos de ofrendas u hoyos pequeños en el piso, tales se diferencian solo por la superposición de pisos una sobre otra manteniendo la relación y la cantidad de postes de madera alineados y aparentemente invertidos, con accesos posiblemente por el extremo NE y un pasadizo por el Norte con un acceso hacia la cuarta plataforma a la que está relacionada, manteniendo el patrón arquitectónico de patios rectangulares, posiblemente de carácter ceremonial, como lo plantea (Ríos y Ccencho, 2009) ubicándolo en la fase constructiva III tardío 3, donde los espacios siguen siendo sagrados con presencia de actividades ceremoniales.

La séptima etapa constructiva está relacionado a accesos restringidos por el extremo Sur a modo de pasadizos, por el extremo Norte sigue manteniendo el patrón arquitectónico, dicho acceso se modifica en cuatro momentos constructivos que están relacionados con un pasadizo, luego superpuesto por un piso y una banqueta al extremo SE, el cual fue modificado por una rampa descendiente hacia el Oeste y luego hacia el Este como todo un sistema de rampas; luego la rampa por el extremo Oeste fue cubierta y convirtiéndola en superficie plana continuando con la rampa de Este a Oeste y Oeste a 
Este como un acceso hacia la sexta plataforma. Este sistema de accesos está relacionado a la fase constructiva IV donde (Ríos y Ccencho 2009) los espacios abiertos están dejando de ser menos sagrados y se tendría poca presencia de actividades ceremoniales.

En la octava etapa constructiva se realizan diferentes cambios en cuanto al acceso y acondicionamientos de recintos, para lo cual se debió destruir elementos arquitectónicos que pertenecieron a atapas más tempranas, del mismo modo reutilizando material constructivo para elaborar estructuras, modificando ciertas técnicas constructivas, como el acondicionamiento de banquetas en un recinto y en pleno pasadizo con accesos de connotación de control hacia la sexta plataforma; para la superposición de estructuras una sobre otras destruyen la anterior, reutilizan los adobes y modifican la estructura en donde depositan cuerpos humanos a modo de sacrificio como una suerte de cambio estructural y etapa constructiva (Barreto 2010)

Del mismo modo, adosan elementos arquitectónicos para el extremo Norte, con una técnica constructiva aparentemente de menor calidad, reestructurando accesos restringidos como pequeñas rampas, y cerrando espacios utilizando materia prima como quincha que no es propio del patrón arquitectónico del sitio; se acondicionan muros y espacios cerrados con presencia de grandes acumulaciones de desechos a modo de rellenos, donde se evidencia fragmentos de cerámica Nieveria, ubicado en el tiempo para la fase IV. Los espacios están siendo mucho más pequeños y los accesos con accesos mucho más restringidos. Con la construcción de recintos pequeños y accesos para un mayor control, constantemente fueron remodelados, con accesos de rampas hacia la sexta plataforma, que constantemente sufren cambios en cuanto a la distribución del espacio, sellando espacios con rellenos de desechos y manteniendo sistemas de pequeños y estrechos accesos hacia el sur, y la construcción de espacios cerrado con presencia de contextos funerarios Wari distribuidos en la quinta y sexta plataforma. ${ }^{2}$

En la pirámide, luego del apogeo reflejado por varias remodelaciones donde se mantiene una unidad constructiva, en las últimas construcciones empieza a producirse un cambio paulatino, que finaliza con un cambio radical y su posterior abandono; los cambios consisten en construcción de ambientes más pequeños, en donde los muros se elaboran delgados y ya no son pintados de color amarillo. Estos cambios también son notorios en la cerámica, aparece un alfar mucho más fino de color anaranjado, el cual se le está denominando Alfar Pucllana Nieveria, es decir que solamente las ultimas construcciones de Pucllana estarían relacionadas con la cerámica de estilo Nieveria. (Flores Et al. 2012:15-18)

Dentro del todo el centro religioso administrativo, existe una secuencia, ligada al proceso de circulación; este proceso de circulación está representado principalmente en sentido Norte-Sur y Este-Oeste; siendo los de más jerarquía los que se ubican en las plataformas más elevadas de la pirámide. En toda esta trayectoria existe una variedad de formas, diferenciadas por su tamaño, forma y disposición-número de banquetas.

El uso de cada una de estos patios debió estar destinado para el desarrollo de actividades en las existe participación de mucho público; pero que en cada una de ellos participan diferente clase de grupos. Estas diferencias pueden notarse hasta dentro de cada uno de los ambientes, en los cuales las

2. Lo cierto es que a partir de la época 7 de los diferentes centros ceremoniales de la cultura Lima empezaron a experimentar cambios en su configuración arquitectónica, muchos de ellos sufrieron remodelaciones mientras en otros aparentemente desaparecieron (Ríos 2008:30) 
banquetas son destinadas a un grupo que tiene un mayor status que el otro (Figura 13). En Lima Tardío, se notan a finales de dicha época, casi en el proceso de abandono, un cambio, ya que se abandona el uso del color amarillo como pintura y las banquetas son más delgadas y elevadas.

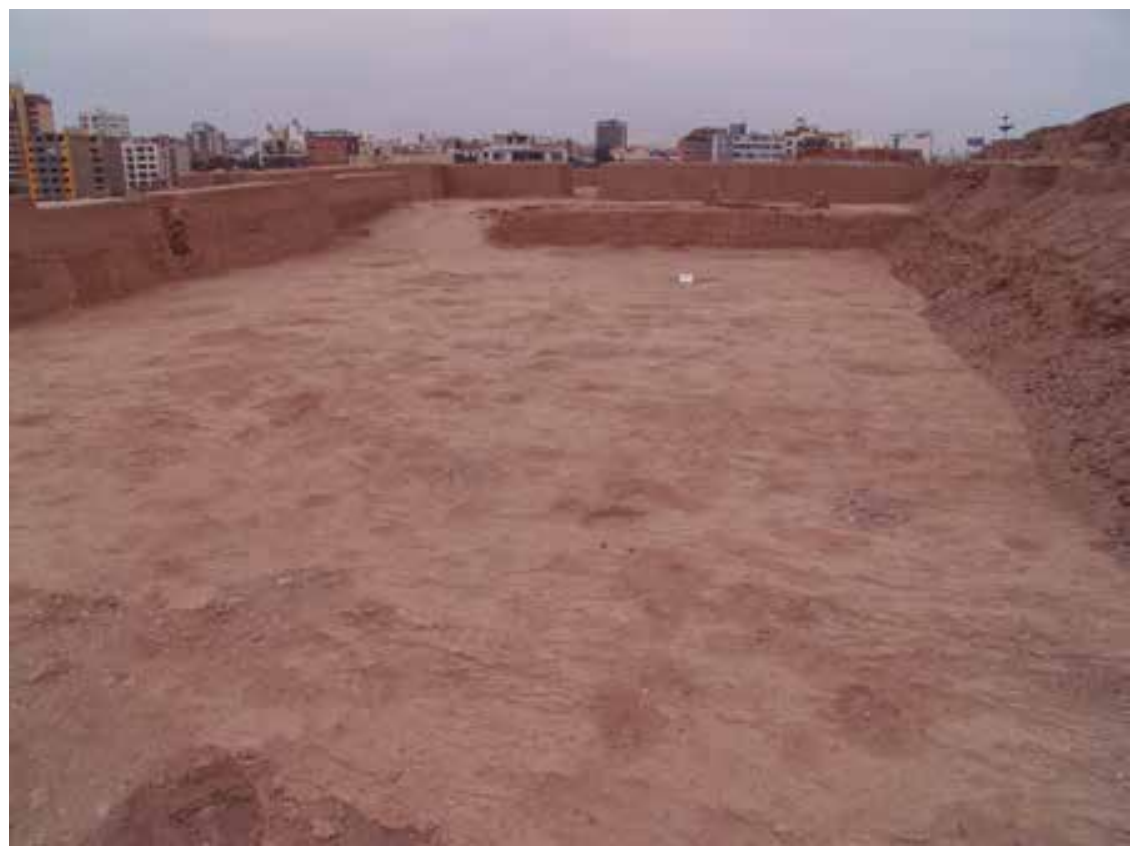

Figura 14: Isometría de la décima primera etapa constructiva.

\section{CONCLUSIONES}

-En la quinta plataforma de la gran pirámide Huaca Pucllana se evidencian espacios arquitectónicos que corresponderían a todo un sistema de patios y accesos, los cuales van sufriendo cambios de una etapa a otra para lo que vendría hacer las últimas etapas de ocupación.

-La mayor ocupación del sitio se da a finales del periodo de Intermedio Temprano e inicios del Horizonte Medio, manifestado esto en la gran densidad de remodelaciones y construcciones realizadas en el sitio entre los años 550 y 680 d.C.

-La arquitectura Lima de la quinta plataforma tiene similitudes con la de la cuarta pues en ambos casos hay una división que separa el espacio en dos áreas con difer entes niveles siempre con patios con banquetas en al menos uno de ellos. Estos cambios se dan agregando y desagregando elementos arquitectos, por tanto cada etapa estaría determinando un tiempo de ocupación correspondiente a un grupo generacional, ya que cada etapa corresponde a un espacio abierto para uso de prácticas ceremoniales.

-El material predominante de construcción en los periodos finales de ocupación del sitio lo constituye el adobito paralelepípedo rectangular, pero también se van a usar adobes paralelepípedos cuadrangulares e incluso cúbicos productos del desmontaje de muros antiguos, estos son reutilizados 
junto a los predominantes. Esto evidenciaría una especie de escasez de la mano de obra de los que elaboran los adobes

- Los cambios en la técnica constructiva para las etapas constructivas más tardías son mucho más simples, reutilizan material constructivo con la destrucción de elementos arquitectónicos, y unidades arquitectónicas antiguos con la finalidad de sellar espacios que pertenecen a etapas de vida.

-La plaza con banquetas y postes del lado Oeste de la quinta plataforma posee características que la hacen especial aunque no posea restos de pintura amarilla en ella. Detalles como la deposición de abundantes desechos en el piso y hoyos de vasijas realizados antes de su enterramiento nos remiten a la jerarquía que debió tener.

-El área fue usada para colocar entierros Wari y también fue usada por los saqueadores para depositar algunos fardos y restos de ellos en hoyos abiertos para ello.

-Los recintos y plazas tienen forma rectangular o trapezoidal y las partes más importantes del edificio son pintadas de color amarillo.

-Las construcciones transicionales muestran descuido en su factura, asimismo los restos de los rituales realizados antes de remodelarlos muestran un decaimiento de este tipo de prácticas. Las etapas constructivas nos están indicando las constantes clausuras de espacios y remodelaciones, manteniendo el uso de los espacios compuestos por patios para prácticas ceremoniales.

\section{Bibliografía}

BARRETO, María; CCENCHO, José; CHUCHÓN, Hilda; SILVERA, Hernán

2010 "Sacrificios Humanos Lima Asociados a la Última Etapa Constructiva de Huaca Pucllana". En: Arqueología y Sociedad N²2, pp.55-72, Museo de Arqueología y Antropología, Universidad Nacional Mayor de San Marcos, Lima.

CCENCHO, José

2007 "Alfar Pucllana Nieveria. Cambios Registrados en una vajilla Ceremonial y sus Implicancias Sociales”. Cuaderno de Investigaciones/ INC, $\mathrm{N}^{\circ}$ 1, pp.17-34. Lima.

2005 Pucllana: esplendor de la Cultura Lima. Instituto Nacional de Cultura, Lima.

FLORES, Isabel; Hilda CHUCHÓN; José CCENCHO y Pedro VARGAS

2012 La doble tela de los muertos. Tejidos especiales Wari de Pucllana. Proyecto de Investigación, Conservación y Puesta en valor de Huaca Pucllana- Auqi Ediciones, Lima.

FLORES, Isabel (compiladora)

2013 Wari en Pucllana: La tumba de un sacerdote. Ministerio de cultura, Lima.

KROEBER, Alfred

1954 “Proto Lima: A Middle Period Culture of Peru". Fieldiana Anthropology 44(1). Chicago Natural History Museum, Chicago.

MARCONE, Giancarlo

2000 "El complejo de Adobitos y la Cultura Lima en el Santuario Pachacamac". Boletín de Arqueología PUCP Huari y Tiwanaku: Modelos vs Evidencias. Primera parte (Petter Kaulicke, \& Willian Isbell) $\mathrm{N}^{\circ}$ 4, pp. 597-605 PUPC, Lima. 
PATTERSON, Thomas Carl

1966 "Pattern and Process in the Early Intermediate Period of The Central Coast of Peru". Anthropology 3; University of California - Berkeley and Los Angeles.

RIOS, Nilton

2008 "Restos de Actividades Rituales en la Segunda Etapa Constructiva de una Plaza Lima Tardío: Un Caso en Pucllana”. Tesis para optar el Título Profesional de Licenciado en Arqueología, Universidad Nacional Mayor de San Marcos, Lima.

RÍOS, Nilton y CCENCHO, José

2009 "Cambios en la sociedad Lima reflejados en la arquitectura del centro Ceremonial de Pucllana durante las primeras épocas del Horizonte Medio: Las evidencias de la Plataforma IV". Arqueología y Sociedad N²0, pp. 91-118, Museo de Arqueología y Antropología, Universidad Nacional Mayor de San Marcos, Lima.

SEGURA, Rafael

2001 "Rito y Economía en Cajamarquilla". Investigaciones Arqueológicas en el Conjunto C. Tello, Fondo Editorial de la Pontificia Universidad Católica del Perú, Lima

VÁSQUEZ, Segundo

1984 “La Waka Pucllana, Lima”. Gaceta Arqueológica Andina N 9, pp.8-9. Instituto Andino de Estudios Arqueológicos. Lima. 